\title{
Obstetrical vacuum extraction practice in Senegal: knowledge, attitude and practices
}

\section{Magatte Mbaye, Mamour Gueye*, Sountou Diaboula, Mame Diarra Ndiaye Gueye, Aliou Diouf, Mouhamadou Wade, Brahem Saheli, Mihimit Abdoulaye, Jean Charles Moreau}

Gynaecologic and Obstetric Clinic, Aristide Le Dantec Teaching Hospital, Cheikh Anta Diop University, Dakar, Senegal

Received: 27 December 2016

Accepted: 31 January 2017

\section{*Correspondence:}

Dr. Mamour Gueye,

E-mail: mamourmb@yahoo.fr

Copyright: ( ) the author(s), publisher and licensee Medip Academy. This is an open-access article distributed under the terms of the Creative Commons Attribution Non-Commercial License, which permits unrestricted non-commercial use, distribution, and reproduction in any medium, provided the original work is properly cited.

\begin{abstract}
Background: Assess knowledge, attitudes and practices of healthcare providers in the three biggest regions in Senegal, appreciate their level of training and determine the frequency of the practice of vacuum extraction in health facilities.

Methods: This was a prospective study conducted over 1 year from January 1 to December 31, 2015 with a survey through interviews using a semi-structured questionnaire with open or closed questions, single or multiple-choice. Were included in the study providers practicing vacuum extractor, officiating in Dakar, Thies and Saint-Louis in the private and/or public sector who agreed to participate in the study. Data were captured and analyzed using File Maker Pro version 12 Inc*, then SPSS (Statistical Package for Social Science) version 21.0.

Results: Out of 250 healthcare providers, 223 accepted to answer the questionnaire leading to an acceptance rate of 89.2\%. 142 healthcare providers $(63.7 \%)$ were trained in vacuum extraction. A proportion of $62.3 \%$ of providers knew the indications of vacuum extraction. For contraindications, only $34.5 \%$ of providers were able to cite one of them. Complications of vacuum extraction were known to $58.7 \%$ of our providers. There was a statistically significant difference between doctors and the others (midwifes, nurses) in the knowledge of indications, contraindications and complications of vacuum extraction. The only discriminatory parameter leading to this difference was initial and continuous training in vacuum extraction.

Conclusions: It is important to introduce obstetric vacuum training in the gynaecology and obstetrics program for medical students and midwifery training schools, reinforce this training using simulators, include the practice of vacuum extraction in the internship objectives of medical students and midwives and evaluate them regularly.
\end{abstract}

Keywords: Knowledge, Practice, Senegal, Vacuum extraction

\section{INTRODUCTION}

A foetal vacuum extractor is a device used to facilitate delivery in term or near term infants. The device enables traction to be applied to the foetal head, in the birth canal, by means of a suction cup that is powered by an external vacuum source. ${ }^{1}$ Vacuum extractor is the 6th function of Emergency Obstetric and Neonatal Care (EmONC) and its application requires a good knowledge of obstetrical mechanics. It is the most used instrumental extraction in the world. ${ }^{2}$

In the literature, many articles have been interested in vacuum extractor with a more didactic than practical approach, focusing more on complications, but also comparing them with other types of instrumental extractions. However, although its practice is subject to different considerations depending on schools, the 
frequency of its use is increasing in the world, especially in the industrialized countries.

In Africa, its use deserves to be improved. In Senegal, a survey carried out between 2012 and 2013 in all health facilities in the country on the availability of EmONC functions showed that vacuum extraction was less used $(4.8 \%)$.

In this way, we decided to assess the knowledge, attitudes and practices of healthcare providers in the three biggest regions in Senegal (Dakar, Thies and Saint-Louis), appreciate their level of training and determine the frequency of the practice of vacuum extraction in the different health facilities.

\section{METHODS}

This was a prospective study conducted over 1 year from January 1 to December 31, 2015 with a survey through interviews using a semi-structured questionnaire with open or closed questions, single or multiple-choice. An investigator administered the questionnaire. The interviews lasted an average of ten (10) minutes and collected socio-demographic profile of the respondent, training received (initial and continuing), knowledge of indications, contraindications and complications of vacuum extractor and level of practice of obstetric vacuum.
Were included in the study providers practicing vacuum extractor (gynaecologists, students in training, midwives or others), officiating in Dakar, Thies and Saint-Louis in the private and/or public sector who agreed to participate in the study. Data were captured and analyzed using File Maker Pro version 12 Inc*, then SPSS (Statistical Package for Social Science) version 21.0.

\section{RESULTS}

Out of 250 healthcare providers, 223 accepted to answer the questionnaire leading to an acceptance rate of $89.2 \%$. These providers mainly worked in health centres, hospitals and private clinics. Data from 25 centres were collected including 8 hospitals, 9 health centres and 8 clinics. The average of deliveries was 2221 for health centres with $0.3 \%$ instrumental vaginal deliveries; 3098.9 for hospitals with $0.97 \%$ of instrumental vaginal deliveries; 412 for clinics with $4.4 \%$ of instrumental vaginal deliveries.

142 healthcare providers $(63.7 \%)$ were trained in vacuum extraction during their study while only 66 providers (29.6\%) performed vacuum extractions during their study. For continuing learning, a quarter of the sample (57 providers, $25.6 \%$ ) participated in a practical vacuum extractor-training course.

Table 1: Distribution of healthcare providers according to knowledge of indications, contraindications and complications of vacuum extractor.

\begin{tabular}{|c|c|c|c|c|c|}
\hline & \multicolumn{2}{|l|}{ Doctors } & \multicolumn{2}{|c|}{ Midwives and others } & \multirow[t]{2}{*}{ p } \\
\hline & Yes & No & Yes & No & \\
\hline Indications & $50(89.3)$ & $6(10.7)$ & $89(53.3)$ & $78(46.7)$ & 0.0001 \\
\hline Contraindications & $38(67.9)$ & $18(32.1)$ & $39(23.4 \%)$ & $128(76.6)$ & 0.0001 \\
\hline Complications & $52(92.9)$ & $4(7.1)$ & $79(47.3)$ & $88(52.7)$ & 0.0001 \\
\hline
\end{tabular}

A proportion of $62.3 \%$ of providers knew the indications of vacuum extraction. For contraindications, only $34.5 \%$ of providers were able to cite one of them. Complications of vacuum extraction were known to $58.7 \%$ of our providers.

There was a statistically significant difference between doctors and the others (midwifes, nurses) in the knowledge of indications, contraindications and complications of the vacuum extractions as shown in the Table 1 . The only discriminatory parameter leading to this difference was initial and continuous training in vacuum extractor. $83.9 \%$ of healthcare providers favoured the teaching of vacuum extraction to all healthcare providers and $92.8 \%$ felt that vacuum extractor should not be used exclusively by obstetrician.

As for safety, $75.8 \%$ of providers did not consider vacuum extraction as a dangerous instrument. No provider was able to specify the suction cup model available in its health facility. The lack of practice was mainly due to two reasons: lack of vacuum extractor $(49.8 \%)$ and lack of training (52.5\%).

\section{DISCUSSION}

A study carried out between 2012 and 2013 throughout Senegal showed that only $15.8 \%$ of providers had undergone training in vacuum extraction. ${ }^{3}$ In health centres and private clinics, forceps rate was higher, unlike hospitals where the rate of vacuum extraction predominated.

A study in Latin America and the Caribbean found that in 2003 , vacuum extraction was unknown to $74 \%$ of health care providers (midwife, obstetrician) and that this mode of delivery was not taught by $52 \%$ of providers from the 111 countries surveyed. ${ }^{4}$ On the other hand, the situation 
in the United States has changed rapidly. Indeed, as early as 1996 , Bofill reported that in the United States, $25 \%$ of students were not trained in the use of the vacuum extraction. ${ }^{5}$ In 2007, the situation was reversed: $80 \%$ of practitioners taught vacuum extraction and only one third taught the forceps. ${ }^{6}$

Instrumental vaginal delivery is a part of the arsenal of skills that every obstetrician must possess. During our survey, vacuum extraction was only used by $18.4 \%$ of healthcare providers. This is justified on the one hand by the lack of competence of our practitioners $(54.7 \%)$ and on the other hand the lack of equipment because out of the 25 centres, only seven facilities had vacuum extraction. It is important to introduce obstetric vacuum training in the Gynaecology and Obstetrics program for medical students and midwifery training schools, reinforce this training using simulators, include the practice of vacuum extraction in the internship objectives of medical students and midwives and evaluate them regularly. On the other hand, it is essential to ensure quality training of physicians specializing in Gynaecology and Obstetrics in the practice of the vacuum extraction and ensure the continuing training of practicing obstetricians and midwives in this practice by regularly organizing training seminars.

\section{CONCLUSION}

It is important to introduce obstetric vacuum training in the gynaecology and obstetrics program for medical students and midwifery training schools, reinforce this training using simulators, include the practice of vacuum extraction in the internship objectives of medical students and midwives and evaluate them regularly.

\author{
Funding: No funding sources \\ Conflict of interest: None declared \\ Ethical approval: Not required
}

\section{REFERENCES}

1. Riethmuller D, Schaal J.P, Maillet R. Ventouse obstétricale: un instrument moderne. Gynecol Obstet Fertil. 2001;29:648-62.

2. Mola G, Amoa A, Edilyong J. Factors associated with success or failure in trials of vacuum extraction. Aust N Z J Obstet Gynecol. 2002;42:35-9.

3. Ndao D. Accouchements par forceps au Senegal: résultats de trois enquêtes sur la couverture obstétrico-chirurgicale du pays (Thèse Med). Dakar: UCAD. 2007;3:79.

4. Fauveau V. Is vacuum extraction still known, taught andpracticed? A worldwide KAP survey. Int J Gynaecol Obstet. 2006;94:185-9.

5. Bofill Ja, Rust Oa, Perry Kg, Roberts We, Martin Rw, Morrisson Jc. Operative vaginal delivery: a survey of fellows of ACOG. Obstet Gynecol. 1996;88:1007-10.

6. Sizer A, Evans J, Bailey S, Wiener J. A second-stage partogram. Obst Gynecol. 2000;96:678-83.

Cite this article as: Mbaye M, Gueye M, Diaboula S, Gueye MDN, Diouf A, Wade M. Obstetrical vacuum extraction practice in Senegal: knowledge, attitude and practices. Int J Reprod Contracept Obstet Gynecol 2017;6:986-8. 